\title{
EMBALAGEM ESPECIAL DE PROTEÇÃO À CRIANÇA: estudo de caso
}

\author{
Gabriel Henrique Cruz Bonfim \\ PPGDesign - UNESP Bauru \\ gh_cb@hotmail.com \\ Luis Carlos Paschoarelli \\ PPGDesign - UNESP Bauru \\ paschoarelli@faac.unesp.br
}

\begin{abstract}
Resumo: O presente estudo baseia-se em um teste de usabilidade, com usuários acima de 60 anos. O objeto de estudo é uma Embalagem Especial de Proteção à Criança (EEPC) conhecida por "push down and turn" (pressione e gire), objetivando a identificação de diferenças entre os gêneros, gerar parâmetros para um design ergonômico e propor melhorias no design das tampas. A tarefa proposta foi abrir e fechar a embalagem. Os resultados mostram que a tarefa mais comprometida é a de abrir o produto. Houve diferença entre os gêneros tanto para abrir como para fechar o produto. Também foram observados problemas na instrução de abertura devido à falta de legibilidade e por não se encontrar na língua vernácula.
\end{abstract}

Palavras-chave: Design, Ergonomia, Usabilidade, Embalagem de proteção.

Abstract: The present study is a usability test with users above 60 years old. The object of study is a Child Resistant Packaging known as "push down and turn", the objective is to identify differences between gender, generate parameters for an ergonomic design and propose improvements in the design of the cap. The proposed task was to open and close the package. The results show that the more committed task is to open the product. There was difference between genders for both open as close to the product. Problems in the opening instructions were also observed due to lack of readability and they were not in the vernacular laguage.

Keywords: Design, Ergonomics, Usability, Child Resistant Packaging 


\section{INTRODUÇÃO}

Não há uma data precisa para o surgimento das embalagens, mas pode-se dizer que seu surgimento se deu nos primórdios da civilização humana. A princípio, o transporte e acondicionamento de produtos era feito de acordo com os materiais disponíveis na época, como couro, folhas e frutos. Com o desenvolvimento de novos materiais e processos, as embalagens passaram a oferecer maior resistência e proteção aos seus conteúdos (SILVA, 2012).

Sabe-se que as principais funções da embalagem são proteger e transportar, mas com o passar dos tempos elas passaram a ter novos objetivos como informar, identificar, promover e vender um produto (NEGRÃO e CAMARGO, 2008).

Apesar desses objetivos, ao se tratar de design de embalagens é importante ter em mente que os usuários possuem habilidades e capacidades distintas. A capacidade de força manual dos usuários é um importante fator a ser considerado no design ergonômico de embalagens, pois dessa forma, é possível garantir produtos confiáveis e seguros, que facilitem o acesso a usuários com capacidades limitadas (idosos) ou dificultem o acesso a crianças para protegê-las de acidentes com o produto.

Entretanto, observa-se que muitos idosos acabam encontrando dificuldades de manuseio devido à redução da força muscular, visto que embalagens possuem diferentes formas de abertura, requerendo diferentes intensidades de forças manuais para serem abertas. (IVERGARD et al, 1979 apud IMRHAN, 1994).

Mesmo com grandes avanços na tecnologia, ainda não existem parâmetros biomecânicos adequados e confiáveis, de todas as faixas populacionais, especialmente no que diz respeito a forças manuais. Isso pode explicar o impedimento dos designers e da indústria de embalagens em oferecer produtos com tampas realmente seguras (DAHROUJ, 2009).

Devido ao grande número de acidentes de intoxicação com crianças menores de 5 anos, surgem as Embalagens Especiais de Proteção à Criança (EEPCs) na tentativa de reduzir tais acidentes. De acordo com Zunjic (2011) a abertura de uma EEPC necessita da perícia e habilidade de um adulto, pois é necessário mais de um movimento para que sejam abertas. No entanto, como mostram alguns estudos, tais embalagens apresentam-se como difíceis de serem abertas por jovens, adultos e principalmente pela população idosa (MCINTIRE et al., 1977; THIEN e ROGMANS, 1984; NAYAK, 2002; DE LA FUENTE, 2006; WINDER, 2009; WARD et al., 2010; ZUNJIC, 2011; BIX e DE LA FUENTE, 2012; YOXALL et al., 2013).

Tendo em vista essa problemática, o objetivo desse estudo foi avaliar a usabilidade de uma EEPC específica conhecida por "push down and turn" (pressione e gire), utilizada na maioria dos polivitamínicos. O estudo foi realizado apenas com usuários idosos (todos acima de 60 anos), para que com os resultados, parâmetros ergonômicos também pudessem ser elencados.

\section{USABILIDADE}

A Usabilidade está descrita na Norma Brasileira de usabilidade NBR 9241-11, sendo definida por uma "medida na qual um produto pode ser usado por usuários específicos para alcançar objetivos específicos com eficácia, eficiência e satisfação em um contexto específico de uso" (ABNT, 2002). A eficácia está relacionada "aos objetivos do usuário quanto à precisão e completude com que estes objetivos podem ser alcançados". A eficiência relaciona o nível de eficácia ao consumo de recursos, 
como por exemplo esforço físico ou mental, tempo, custos materiais ou financeiros. Já a satisfação "mede a extensão pela qual os usuários estão livres de desconforto e suas atitudes em relação ao uso do produto" (ABNT, 2002), sendo esta a mais difícil de se avaliar, pois é subjetiva.

O contexto de uso engloba os usuários, as tarefas, os equipamentos e o ambiente de uso. A descrição de cada um deles é muito importante para a avaliação da usabilidade.

Segundo Moraes (2001) e lida (2005) a usabilidade está sujeita à interação entre o produto, o usuário, a tarefa e o ambiente, havendo a necessidade de adequação entre cada um deles. Para Gomes (2006) a usabilidade está relacionada a cinco atributos: facilidade de aprendizagem, eficiência, facilidade de relembrar mesmo depois de um longo tempo sem uso, redução de erros, e satisfação.

Uma relação entre ergonomia e o surgimento da usabilidade é feita por Cybis et al. (2010), pois a ergonomia busca proporcionar eficácia, eficiência e bem estar aos usuários, tendo como objetivo a adaptação de sistemas e dispositivos ao homem, para que possam lhe proporcionar usabilidade. No momento em que os usuários empregam o sistema para alcançar seus objetivos em um determinado contexto de uso, é quando se mostra a usabilidade, onde poderão ser avaliadas a eficácia, eficiência e satisfação. A diferença entre elas está no fato de que a usabilidade é medida, enquanto que a ergonomia das interfaces é avaliada por recomendações e critérios ergonômicos (CYBIS et al., 2010).

\section{PLANEJAMENTO}

Para melhor compreensão e definição do estudo, foi feito um planejamento para deixar claro como se daria o teste de usabilidade do produto escolhido.

Em primeiro lugar o pesquisador, que foi tido como o perito ${ }^{1}$ do estudo, abriu e fechou o produto enquanto era filmado. Através do vídeo, o tempo de realização de cada etapa da tarefa foi contabilizado.

Sendo assim, definiu-se como objetivo do estudo testar a eficácia e eficiência do produto, bem como sua capacidade de satisfazer o usuário. O local de realização dos testes seria a residência unifamiliar de cada um dos sujeitos participantes. 0 tempo de duração de cada teste seria de 10 minutos, dos quais 5 serviriam para a realização da tarefa e os outros 5 para responder os protocolos. Os equipamentos utilizados seriam uma embalagem de polivitamínico com tampa do tipo "pressione e gire" e câmera digital.

O início do teste se dá quando o indivíduo toca o produto. Para participar do estudo, os indivíduos deveriam ter no mínimo 60 anos podendo ser do gênero masculino ou feminino, sendo que o número mínimo de sujeitos para o teste seria de 5 pessoas.

A tarefa a ser desempenhada no teste foi dividida em duas etapas: abrir e fechar a embalagem. O pesquisador deveria manter-se neutro enquanto o indivíduo realizava o teste, ou seja, não poderia dar nenhum tipo de ajuda. Após a realização dos testes, serão analisados os vídeos de cada sujeito, as informações verbais, as observações sistemáticas e os protocolos aplicados.

\footnotetext{
${ }^{1}$ Perito é o indivíduo que conhece os aspectos técnicos do produto que está sendo testado.
} 


\section{MATERIAL E MÉTODO}

\subsection{Aspectos Éticos}

Por se tratar de uma pesquisa com seres humanos, os aspectos éticos foram atendidos, com a aplicação de um Termo de Consentimento Livre e Esclarecido (TCLE), o qual foi previamente aprovado pelo Comitê de Ética e Pesquisa da Universidade do Sagrado Coração de Bauru, atendendo o "Código de Deontologia do Ergonomista Certificado - Norma ERG BR 1002", da ABERGO (2003).

\subsection{Sujeitos}

Os participantes do estudo foram 10 sujeitos idosos (com idade superior ou igual a 60 anos), sendo que metade era do gênero masculino e a outra metade era do gênero feminino. A idade média dos sujeitos foi de 70,3 anos com um desvio padrão de 9,04 anos. Essa amostra foi baseada em estudos como o de Nielsen (1993) e de Tullis e Albert (2008), nos quais amostras de 6 a 12 pessoas são apresentadas como suficientes.

\subsection{Materiais}

Para a obtenção de informações como nome, data de nascimento, lateralidade, formação escolar e possíveis sintomas músculo esqueléticos nos membros superiores, foi elaborado um protocolo de identificação.

O produto avaliado foi uma embalagem de um polivitamínico (Figura 1) vendida na maioria das farmácias do Brasil. Esse produto foi escolhido por se tratar de uma Embalagem Especial de Proteção à Criança (EEPC) cujo sistema de abertura é do tipo "pressione e gire" ("push down and turn"), no qual o usuário deve pressionar a tampa contra o corpo do produto e realizar um movimento de rotação simultâneo para que o produto possa ser aberto.

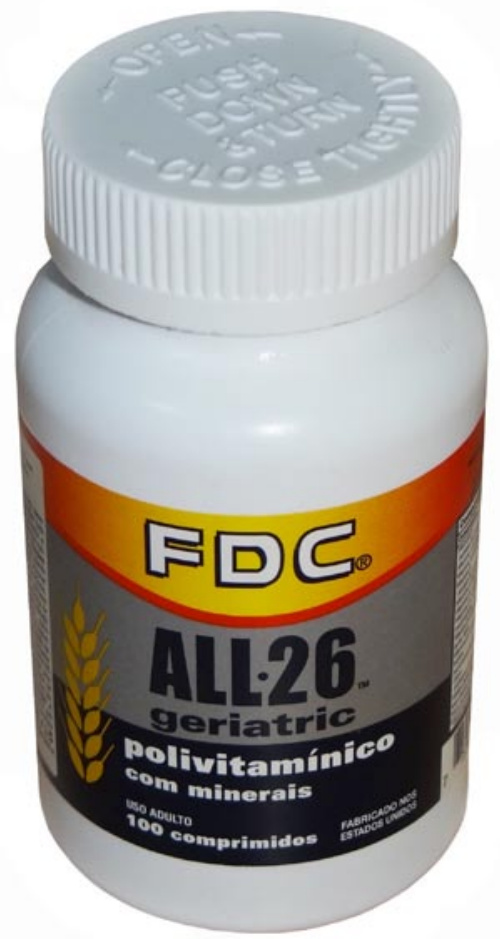

Figura 1 - Embalagem selecionada para o estudo

Fonte: Elaborado pelo autor, com base na pesquisa realizada 
A Figura 2, mostra o Protocolo SUS (System Usability Scale) que foi elaborado para avaliação do grau de satisfação. Esse protocolo foi dividido em duas colunas, a coluna da esquerda era composta de 10 sentenças divididas em positivas e negativas em relação ao produto. A coluna da direita era composta de uma escala de 5 pontos que variava de "Discordo totalmente" a "Concordo totalmente", sendo assim, após ler cada uma das sentenças, o indivíduo deveria apontar se concordava ou discordava daquela sentença, posicionando-se em algum dos 5 pontos da escala.

\section{PROTOCOLO SUS}

De acordo com o produto que você acabou de utilizar, assinale um único ponto da escala (coluna à direita), correspondente às afirmações apresentadas na coluna à esquerda.

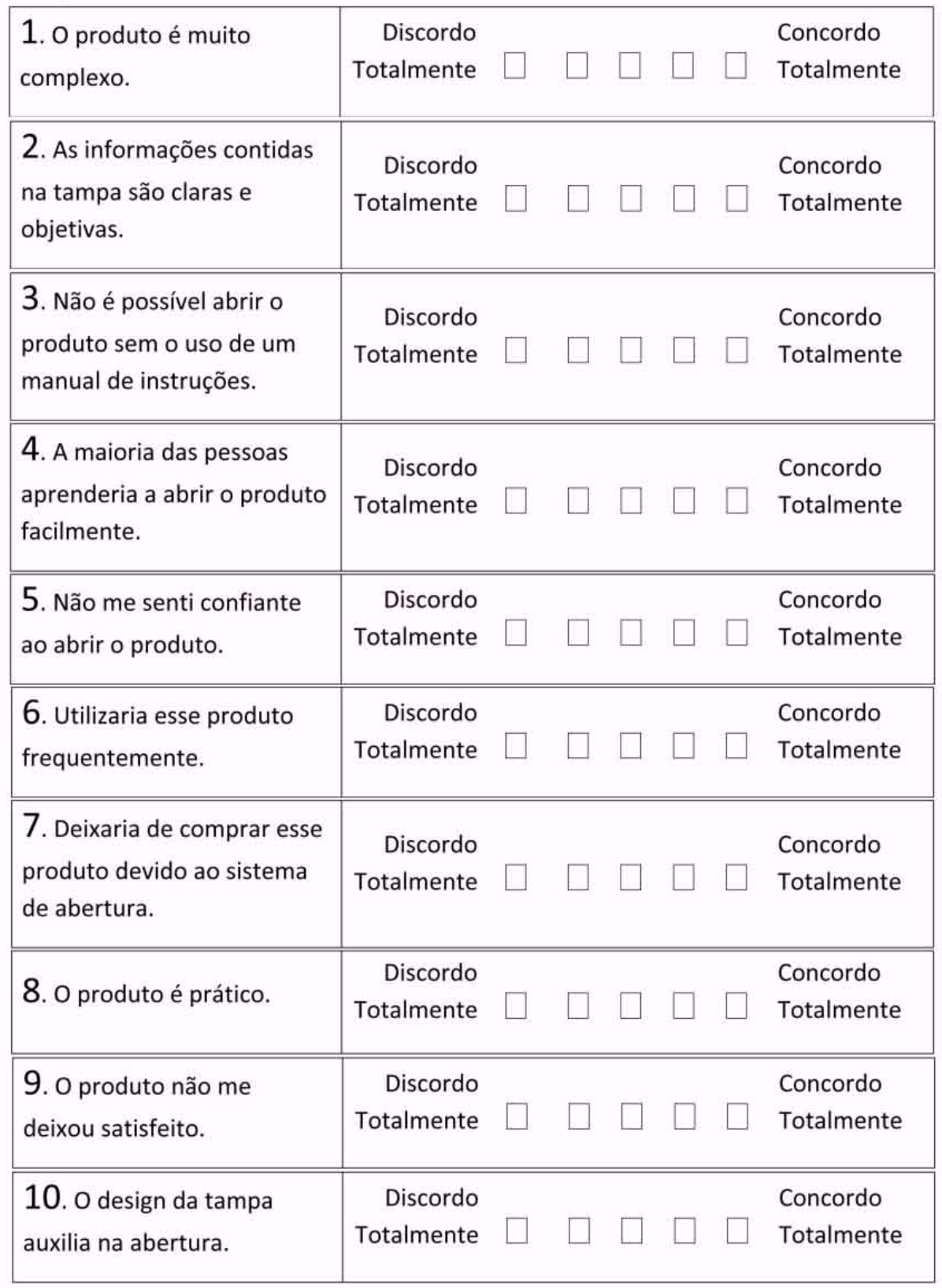

Figura 2 - Protocolo SUS

Fonte: Elaborado pelo autor, com base na pesquisa realizada 
Uma câmera digital foi utilizada para filmar os indivíduos durante a realização da tarefa, para que, através de uma análise posterior, os tempos de cada etapa pudessem ser contabilizados, bem como expressões faciais e principais reações de cada sujeito perante o produto avaliado.

\subsection{Procedimentos}

Os sujeitos eram abordados e lhes eram explicados os objetivos da pesquisa, bem como os procedimentos do teste de usabilidade a ser realizado. Em seguida, liam e preenchiam o TCLE. Na sequência, era apresentado o Protocolo de Identificação que também era lido e preenchido pelos participantes.

Através da câmera digital, o procedimento passava a ser gravado. Então, o produto era apresentado e perguntado se os indivíduos já o conheciam, se já haviam aberto aquele tipo de embalagem e se achavam que ela parecia fácil e prática de ser aberta. Depois das perguntas, o teste de usabilidade era realizado da seguinte maneira: os sujeitos deveriam realizar uma tarefa dividida em 2 etapas - abrir e fechar o produto.

Quatro perguntas eram feitas após a interação dos sujeitos com o produto:

1- Quanto à sua expectativa, o uso da embalagem foi mais fácil do que o esperado?

2- Você sentiu desconforto ao abrir o produto? Onde?

3- Se você não conseguisse abrir essa embalagem, o que faria em sua casa para abri-la?

4- Você têm alguma sugestão de melhoria para a embalagem?

Em último lugar, o Protocolo SUS era preenchido de acordo com a experiência de cada sujeito com o produto.

\subsection{Procedimento de análise dos dados}

Finalizados os testes, o tempo foi contabilizado e as atividades, desvios ${ }^{2}$ e erros foram descritos com a ajuda dos vídeos.

Assim como descritas na norma, as medidas de usabilidade avaliadas nesse estudo foram: eficácia, eficiência e satisfação. Para análise da eficácia foi considerado a tarefa completada com sucesso (abrir e fechar a embalagem). Para a análise da eficiência, foi considerado o tempo total de execução da tarefa em relação ao tempo do pesquisador (perito). Para a análise de satisfação, o Protocolo SUS foi analisado de acordo com os procedimentos descritos em Tullis e Albert (2008).

O restante dos dados foram tabulados e analisados para verificação de influência nos diferentes gêneros.

\section{RESULTADOS}

Com relação às três perguntas iniciais feitas antes da interação com o produto observou-se que a maioria dos sujeitos (60\%) não conhecia a embalagem, e nem todos que conheciam haviam tido contato com o produto, pois $80 \%$ nunca haviam aberto o produto. E para a maior parte dos usuários (90\%), a embalagem não parecia ser simples de ser aberta.

\footnotetext{
${ }^{2}$ Entende-se por desvio, a realização da tarefa de modo diferente do padrão.
} 
Após entrarem em contato com o produto, metade (50\%) dos usuários achou que a embalagem era mais difícil de ser aberta do que esperava.

Em relação ao desconforto na abertura do produto, observou-se que apenas $20 \%$ dos sujeitos reclamaram de desconforto ao abrir a embalagem, mais especificamente nos dedos e na palma da mão. No entanto, as gravações mostraram que outros usuários também reclamaram de incômodo no momento em que tentavam desrosquear a tampa, mas não relataram desconforto no questionário.

A Figura 3, mostra o que os sujeitos fariam caso não conseguissem abrir a embalagem.

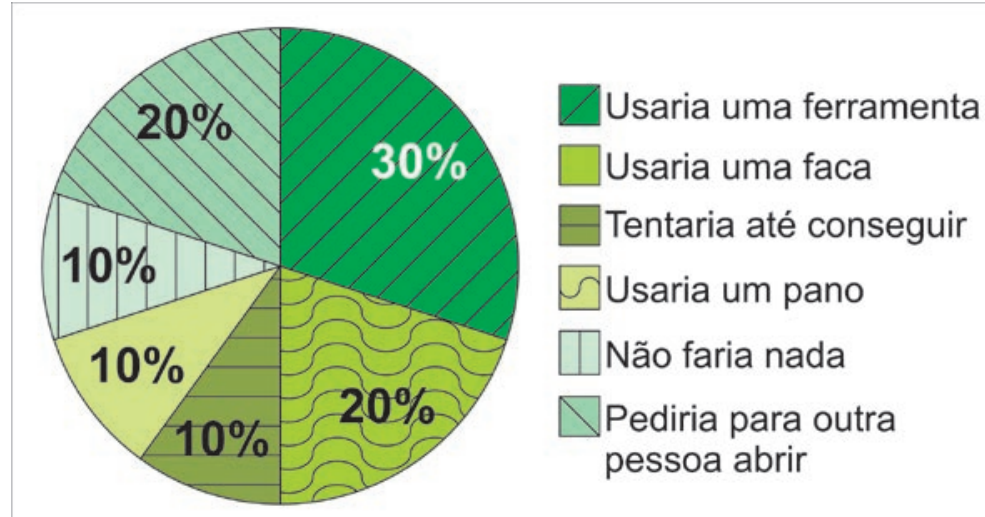

Figura 3 - Atitudes dos sujeitos caso não abrissem a embalagem

Fonte: Elaborado pelo autor, com base na pesquisa realizada

Observa-se que $40 \%$ dos participantes usariam uma ferramenta ou faca, o que pode causar sérios acidentes e problemas para o usuário. O restante (60\%) buscaria meios mais seguros para abrir o produto.

Por fim, as sugestões de melhoria foram para colocar as instruções de abertura em língua vernácula e apenas um usuário disse para retirar o sistema de segurança do produto.

\subsection{Medidas de usabilidade}

Como já citado anteriormente, sabe-se que as medidas de usabilidade são: eficácia, eficiência e satisfação. Cada uma delas será abordada individualmente a seguir.

\subsubsection{Eficácia}

As medidas de eficácia foram consideradas de acordo com a precisão e completude com que os objetivos dos sujeitos foram alcançados. É importante lembrar que os objetivos da tarefa desse experimento eram: abrir e fechar a embalagem.

Notou-se que apenas 1 usuário não conseguiu completar a tarefa, pois não abriu o produto. Entretanto alguns desvios foram observados durante a realização das etapas, mostrando que nem todas foram feitas com precisão.

$\mathrm{Na}$ etapa de abertura, dois usuários (20\%) primeiramente tentaram puxar a tampa ao invés de pressionar. Nessa mesma etapa, outros 2 usuários (20\%) conseguiram desencaixar a tampa do sistema de proteção interno (Figura 4) em seguida desrosquearam a proteção da embalagem para abrir. Os outros conseguiram abrir normalmente. Na etapa de fechar a embalagem, 1 usuário (10\%) pressionou a 
tampa contra o corpo do produto com muita força até entender que precisava apenas rosquear. Os 2 usuários (20\%) que conseguiram desencaixar a tampa do sistema de proteção interno, primeiramente posicionaram o sistema de proteção sobre o corpo da embalagem e em seguida colocaram a tampa por cima, depois pressionaram a tampa com força para que pudesse encaixar novamente no sistema de proteção e assim puderam rosquear e fechar o produto.

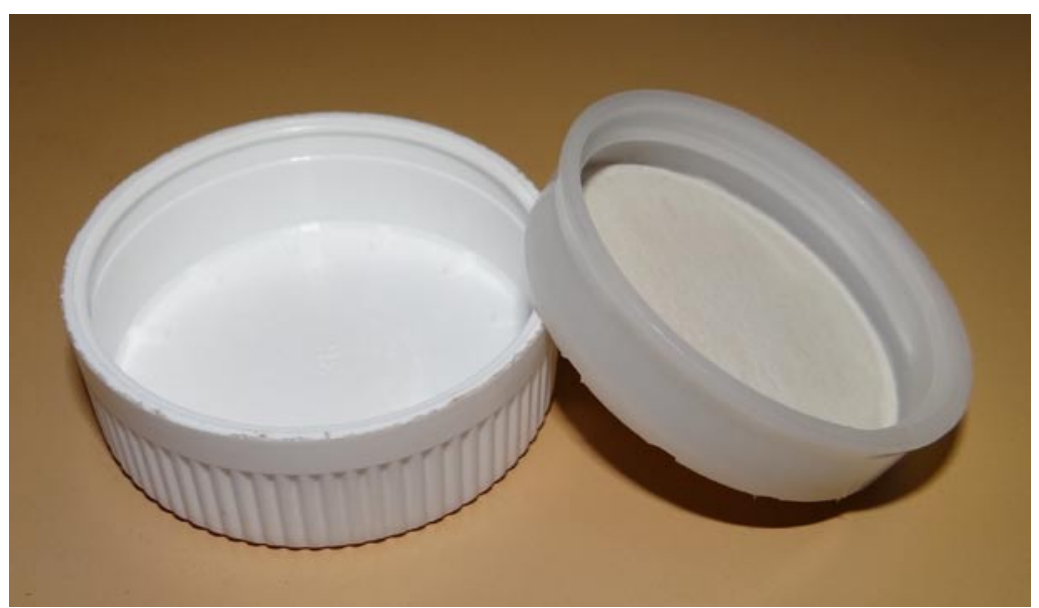

Figura 4 - Tampa desacoplada do sistema de proteção

Fonte: Elaborado pelo autor, com base na pesquisa realizada

\subsubsection{Eficiência}

As medidas de eficiência foram analisadas relacionando o nível de eficácia alcançada com o consumo de tempo.

Uma das dificuldades apresentadas pelos usuários, foi conseguir entender qual era a informação contida na tampa do produto (Figura 5). Muitos chegaram a observala, porém não entenderam perfeitamente o que era e alguns não abriram o produto da maneira correta. A maior dificuldade dos usuários de deu pelo fato de as instruções de abertura não estarem em língua vernácula, além disso figura e fundo são exatamente da mesma cor, o que dificultou ainda mais a visualização, pois idosos normalmente apresentam problemas de visão são mais acentuados.

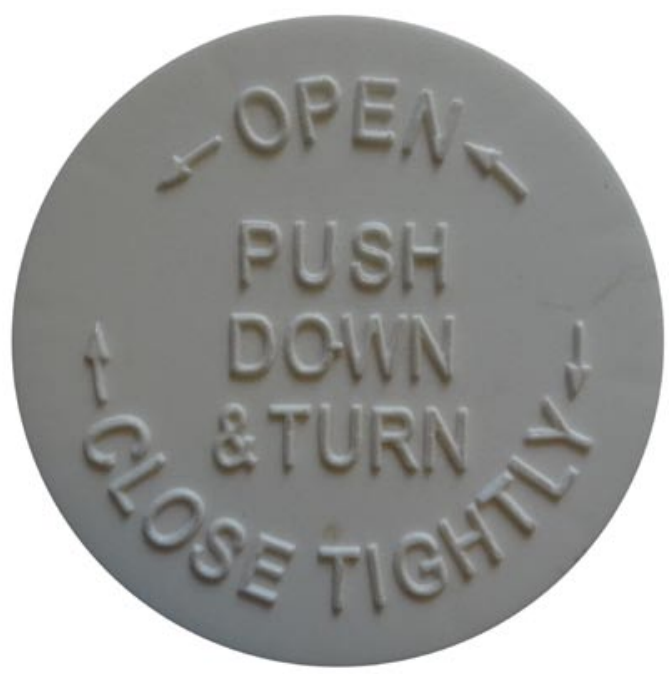

Figura 5 - Instruções de abertura da tampa do produto

Fonte: Elaborado pelo autor, com base na pesquisa realizada 
A Figura 6 mostra os gráficos de abertura e fechamento da embalagem, comparando o tempo (em segundos) do perito com o tempo dos sujeitos.

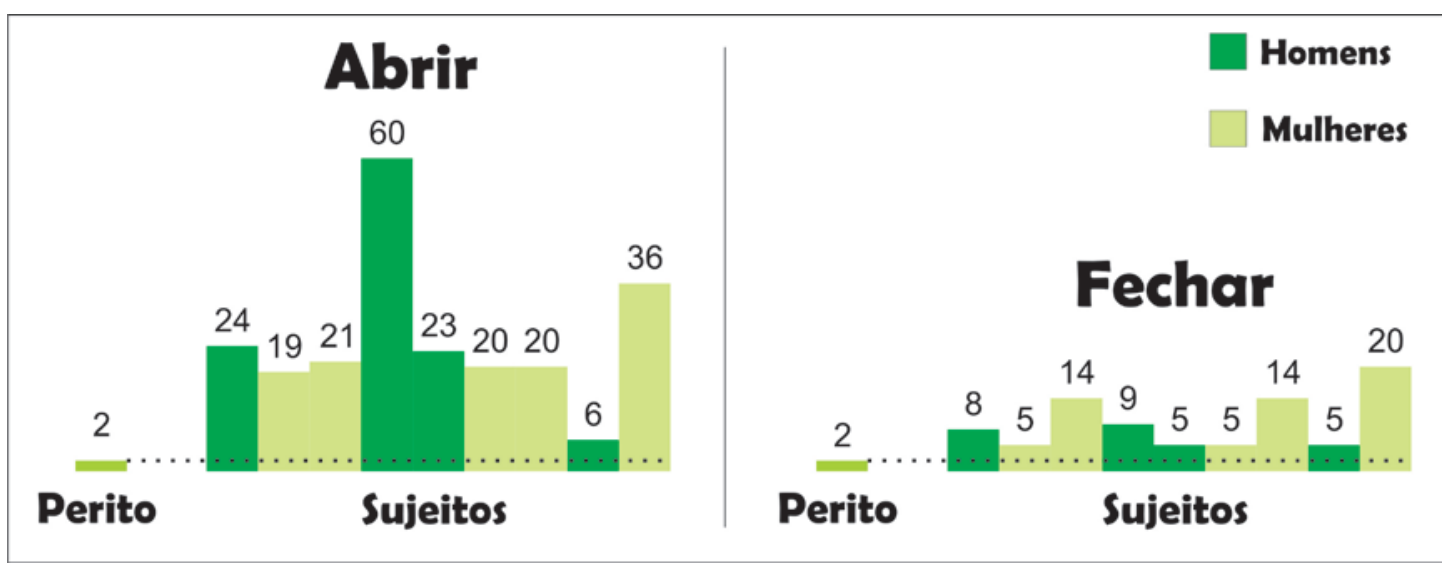

Figura 6 - Comparação do tempo (segundos) de abertura do produto

Fonte: Elaborado pelo autor, com base na pesquisa realizada

Observa-se que a etapa que os sujeitos mais demoraram para realizar foi a de abrir o produto. É importante ressaltar que um dos sujeitos não conseguiu abrir a embalagem, por isso seu tempo não foi contabilizado em nenhum dos gráficos. Notase também que a média do tempo dos homens foi maior que a das mulheres na abertura, entretanto o contrário ocorre na etapa de fechar o produto.

De maneira geral, encontrando-se a média do total do tempo dos sujeitos pode-se dizer que ela foi aproximadamente 9 vezes maior que o tempo do perito. A Figura 7 apresenta o gráfico com o tempo total da tarefa realizada pelo perito em comparação com os sujeitos.

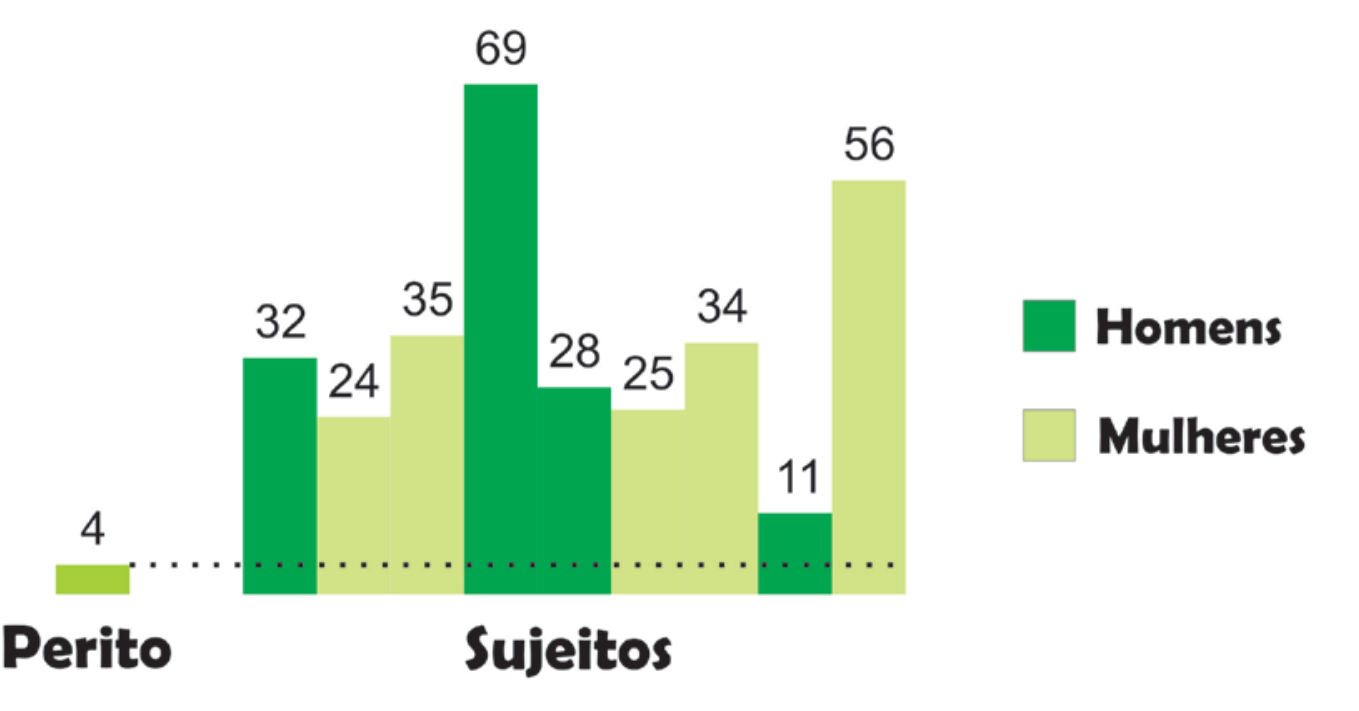

Figura 7 - Comparação do tempo total (segundos) para realização da tarefa

Fonte: Elaborado pelo autor, com base na pesquisa realizada

Cabe salientar que ao se comparar as médias do tempo das mulheres e dos homens, os resultados foram iguais. 


\subsubsection{Satisfação}

A satisfação é uma medida subjetiva, por isso adotou-se o protocolo SUS para averiguação dessa medida de usabilidade. O cálculo desse protocolo se dá de acordo com Tullis e Albert (2008).

Após a análise do protocolo SUS a média de satisfação obtida foi de $51,75 \%$. No entanto, notou-se que a média de satisfação é diferente para os gêneros. A Figura 8 mostra um infográfico com as médias de satisfação dos gêneros.

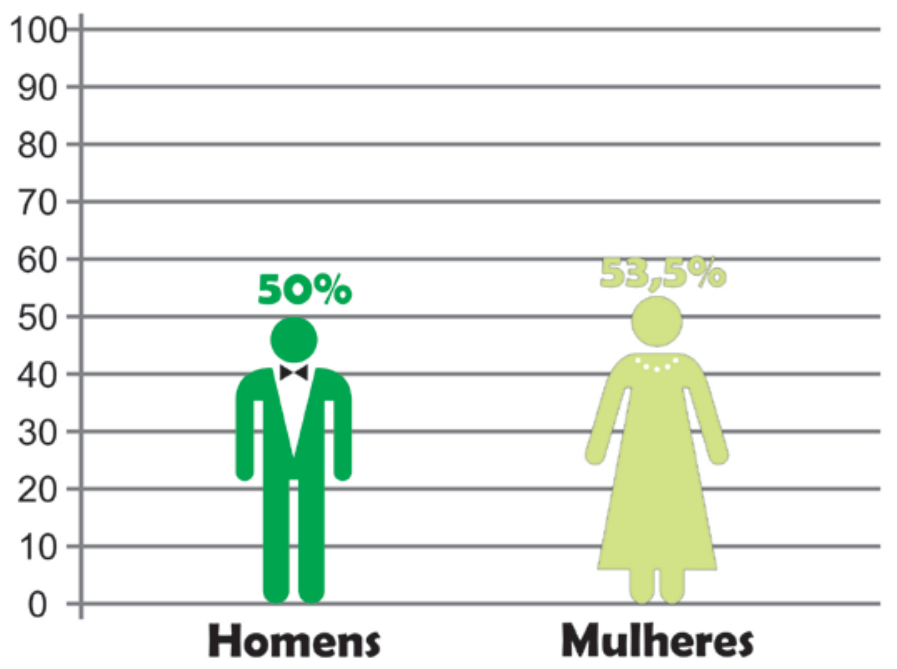

Figura 8 - Infográfico do nível de satisfação por gênero

Fonte: Elaborado pelo autor, com base na pesquisa realizada

É curioso observar que a satisfação dos homens foi menor que a das mulheres, pois geralmente os homens acabam exercendo maior força para tentar abrir um produto quando este parece ser difícil de abrir, entretanto, a realização de muita força para abrir essa embalagem é indiferente, porque se a tampa não for pressionada corretamente ela não abre. Isso pode ter gerado certa frustração nos homens.

\section{Conclusão}

Embalagens Especiais de Proteção à Criança surgiram com o intuito de minimizar os riscos de intoxicação, entretanto tais embalagens acabaram se tornando um empecilho para a população idosa. Assim sendo, esse estudo busca mostrar a importância de uma análise ergonômica em embalagens, visando o melhor acordo entre usuário, interface e tarefa. E através do teste de usabilidade, pode-se notar o comportamento e atitudes do usuário perante dificuldades apresentadas na interação com o produto.

Um bom projeto de embalagem que atenda as necessidades especiais de usuários idosos considerando suas capacidades e habilidades específicas, bem como um projeto que dificulte o acesso a crianças priorizando sua segurança, pode ser realizado através da observação de parâmetros e recomendações ergonômicas.

O presente estudo mostrou que a etapa mais comprometida foi a de abrir a embalagem, visto que a maioria dos usuários não conseguiu entender e seguir as instruções de abertura presentes na tampa, já que essa embalagem possui um sistema de proteção à criança e necessita da realização de mais de um movimento para ser aberta. Entretanto, as informações contidas na tampa estão em inglês, além de serem difíceis de serem notadas. Sugere-se que tais instruções sejam escritas em língua 
vernácula e que haja um destaque melhor da parte escrita, preferencialmente em cor preta, para que ocorra um melhor contraste entre figura e fundo.

Observou-se também que as usuárias do gênero feminino realizaram a tarefa em menos tempo que os homens e por consequência sentiram-se mais satisfeitas com o produto do que os usuários do gênero masculino.

Nota-se também, que parte dos usuários, apesar de terem tido certa dificuldade em abrir o produto, não relataram nenhum tipo de problema. Esse fato é comum em usuários da terceira idade que, mesmo quando encontram algum problema ou dificuldade em relação à interface de um produto, acabam suprimindo tal informação.

Além disso, foi possível confirmar, através dos relatos dos participantes, que usuários idosos buscam meios mais seguros para abrirem os produtos, apesar de que 0 uso de instrumentos cortantes ainda continua sendo uma opção para alguns deles.

No geral, o estudo mostrou-se pertinente e cumpriu com os objetivos pretendidos, no entanto ainda há uma carência de estudos que avaliem a acessibilidade de Embalagens de Proteção, especialmente para a população idosa.

\section{Agradecimentos}

Este estudo foi desenvolvido com apoio da CAPES e CNPq.

\section{REFERÊNCIAS}

ABERGO. Norma ERG BR 1002 - Código de Deontologia do Ergonomista Certificado. Associação Brasileira de Ergonomia, 2003. Disponivel em: <http://www.abergo.org.br/arquivos/normas_ergbr/norma_erg_br_1002_deontologia .pdf>. Acesso em: 13 nov 2013.

ABNT - Associação Brasileira de Normas Técnicas. Requisitos Ergonômicos para Trabalho de Escritórios com Computadores. 2002. NBR 9241 Parte 11 - Orientações sobre Usabilidade. Disponível em: http://www.inf.ufsc.br/ cybis/pg2003/iso924111F2.pdf. Acesso em 15 de março de 2012.

BIX, L. e DE LA FUENTE, J. Perceptions and Attitudes of People with Disabilities and Older Adults about Child-resistant Drug Packaging. Journal For Patient Compliance, v. 2, n. 2, p. 54-59, 2012.

CYBIS, W.; BETIOL, A. H.; FAUST, R. Ergonomia e Usabilidade: Conhecimentos, Métodos e Aplicações. 2a. ed. São Paulo: Novatec, 2010.

DAHROUJ, L. S. Avaliação de força de torção manual infantil: O design ergonômico aplicado ao desenvolvimento de tampas seguras para embalagens de domissanitários. 2009. 82f. Dissertação (Mestrado em Desenho Industrial) - UNESP, Bauru. 2009.

DE LA FUENTE, C. J. The use of a universal design methodology for developing childresistant drug packaging. 2006. 198f. Dissertação (Master in Packaging) - School of Packaging, Michigan State University, East Lansing. 2006. 
IIDA, I. Ergonomia: projeto e produção. 2a. ed. Rio de Janeiro: Edgard Blucher, 2005.

IMRHAN, S. N. Muscular strength in the elderly - Implications for ergonomic design. International Journal of Industrial Ergonomics, v. 13, p. 125-138, 1994.

MCINTIRE, M. S.; ANGLE, C. R.; SATHEES, K.; LEE, P. S. T. Safety Packaging - What Does the Public Think? American Journal of Public Health, v. 67, n. 2, p. 169-171, 1977.

MORAES, A. Ergonomia e usabilidade de produtos, programas, informação: área de concentração, linhas de pesquisa, projetos de pesquisa, ideias, realizações, produção e competências. In: MORAES, A. D.; FRISONI, B. C. Ergodesign: produtos e processos. Rio de Janeiro: $2 A B, 2001$. p. 9-50.

NAYAK, L. U. S. Can Older Adults use Child Resistant Bottle Closures? Gerontechnology Journal, v. 2, n. 2, p. 198-202, 2002.

NEGRÃO, C.; CAMARGO, E. Design de embalagem: do marketing à produção, São Paulo: Novatec Editora, 2008.

NIELSEN, J. Usability Engineering. Boston: Academic Press, 1993.

SILVA, D. C. 2012. A influência do design na aplicação de forças manuais para abertura de embalagens plásticas de refrigerantes. 120 f. Dissertação (Mestrado) Curso de Mestrado em Design, Universidade Estadual Paulista "júlio de Mesquita Filho", Bauru, 2012.

THIEN, W. M. A.; ROGMANS, W. H. J. Testing child Resistant Packaging for Access by Infants and the Elderly. Accident Analyses \& Prevention, v. 16, n. 3, p. 185-190, 1984.

TULLIS, T. e ALBERT, B. Measuring the user experience: collecting, analyzing, and presenting usability metrics. Burlington: Morgan Kauffman, 2008.

WARD, J.; BUCKLE, P.; CLARKSON, P. J. Designing packaging to support the safe use of medicines at home. Applied Ergonomics, v. 41, p. 682-694, 2010.

WINDER, B. The design of packaging closures. In: THEOBALD, N.; WINDER, B. (Ed). Packaging Closures and Sealing Systems. Blackwell Publishing Ltda, 2009. p. 36-67.

YOXALL, A.; RODRIGUEZ-FALCON, E. M.; LUXMOORE, J. Carpe diem, Carpe ampulla: A numerical model as an aid to the design of child-resistant closures. Applied Ergonomics, v. 44, n. 1, p. 18-26, 2013.

ZUNJIC, A. Ergonomics of Packaging. In: KARWOWSKI, W.; SOARES, M. M.; STANTON, N. A. (Org.). Human factors and ergonomics in consumer product design: uses and applications. Boca Raton: CRC Press. 2011. p. 101-123. 